E-MAIL CONTRIBUTIONS

\title{
UK parliament to pick up women in science debate
}

\section{SARAHPEARCE}

UK Parliamentarians have recently expressed an interest in this issue. A debate took place in July 1998 in the House of Commons on Women in Science and Engineering. During the debate, the then Minister for Science, Energy and Industry, John Battle MP, said: "We must not continue to risk wasting the talents of more than half the population. If we do not allow women's talents to be fully developed, we shall jeopardise our future. Women are significantly under-represented in almost every area of research and employment in science, engineering and technology. In those areas, women work disproportionately in junior positions. There is little room at the top for women in science, and that must change."

The debate also covered many of the other topics mentioned in this Nature debate, such as the need for role models, family friendly policies and difficulties for women in gaining grants and promotion. Issues of concern for the UK included the insecurity related to fixed-term contracts, and the desire to increase representation on public bodies, councils and committees in science-related fields. There was also discussion of the need for the Government to monitor all its science spending for equal opportunities.

The House of Lords Science and Technology Committee is currently conducting an enquiry into 'Science and Society'. The Parliamentary Office of Science and Technology (POST) recognised women in science as a relevant issue for this enquiry, and plans to conduct an on-line consultation on Science, Technology, Engineering and Women in the UK.

POST will submit a report on this consultation to the Lords Committee. As with all Parliamentary Committees' reports, there will be, in due course, a government response to the Committee's recommendations and a debate in Parliament.

The on-line consultation is intended to enable scientists and others interested in the role of women in science, engineering and technology research and education, to have a national dialogue on key themes relevant to the Committee's enquiry. Many of the points raised in the Nature debate are also germane to the Lords enquiry. However, the Lords consultation will focus primarily on issues relevant to UK policy -- although there is always an interest in other innovative projects.

Participants and observers in the Nature debate are welcome to join the online consultation. The discussion is most definitely not intended to be restricted to the academic world -- participants from private and public research institutes and the commercial world are warmly invited. Participation is also welcomed from both sexes. Details of the consultation are given in the panel below.

\section{Sarah Pearce}

Adviser Physical Sciences and Information Technology

UK Parliamentary Office of Science and Technology

The discussion will run over three weeks from 25th October to 12th November, with each week devoted to a specific theme. Each theme will be introduced by a keynote contribution from a leading figure in that field. 
- Week 1 Education: primary, secondary and higher education - first choices, first constraints, first barriers.

- Week 2 Career: fulfilling potential, overcoming frustration.

- Week 3 Culture: does science suffer from its gender imbalance?

A record of the discussion will be available on the World Wide Web. After submission of its report to the Lords Science and Technology Committee, POST will, (subject to the Committee's agreement) also place this report on its web site.

The discussion will be hosted by the UK universities' 'Mailbase' system and will be accessed by e-mail. Potential participants will need to register to join the discussion list.

For further general information, and details of how to join, see the Mailbase web site at: http://www.mailbase.ac.uk/lists/hansard

The on-line consultation is a collaboration by the Hansard Society (http://www.hansardsociety.org.uk), the Women in Higher Education Register (http://www.where.ic.ac.uk) and the Parliamentary Office of Science and Technology

(http://www.parliament.uk/post/home.htm).

Nature (C Macmillan Publishers Ltd 1999 Registered No. 785998 England. 